“Neutralistas" y "políticos". Los debates en el Partido Socialista argentino acerca de la relación entre partido y sindicato, $1901-1904$. Lucas POY

Avances del Cesor, V. XIII, No 15, Segundo semestre 2016, pp. 19-38.

ISSNe 2422-6580 / ISSN 1514-3899 - http://web2.rosario-conicet.gov.ar/ojs/index.php/AvancesCesor/index

\title{
"Neutralistas" y "políticos". Los debates en el Partido Socialista argentino acerca de la relación entre partido y sindicato, 1901-1904
}

\section{"Neutralists" and "Politicals". The debates inside the Argentine Socialist Party about the relationship between party and union, 1901-1904}

\author{
Lucas Poy \\ Consejo Nacional de Investigaciones Científicas y Técnicas \\ Instituto de Historia Argentina y Americana "Dr. Emilio Ravignani" \\ Universidad de Buenos Aires \\ Argentina \\ lucaspoy@gmail.com
}

(2)

\section{Resumen}

$\mathrm{El}$ artículo examina las tensiones internas que surgieron, en los primeros años del siglo $\mathrm{XX}$, al interior del Partido Socialista argentino a propósito de la relación entre lucha económica y lucha política y, en particular, del problema de cómo actuar al interior de los gremios. Para ello rastrea un debate que se desenvolvió con fuerza en los años 1902 a 1904 y enfrentó a los partidarios de la "neutralidad" en los sindicatos con aquellos defensores de una más decidida intervención política en los mismos. El debate, de carácter propagandístico y teórico, estuvo por otro lado vinculado al proceso de constitución de la Unión General de Trabajadores. Apuntamos a contribuir a nuestro conocimiento sobre las disputas que configuraron al Partido Socialista en el período crítico del cambio de siglo, así como a entender las particularidades de la tensión interna que llevaría a la ruptura de los sindicalistas revolucionarios.

Palabras Clave: Partido Socialista - Sindicatos - Sindicalismo - Socialdemocracia 


\begin{abstract}
The article explores the internal tensions that emerged in the early twentieth century, inside the Argentine Socialist Party, regarding the relationship between the economic and the political struggle-and, in particular, the politics inside the unions. In so doing, it examines a debate that took place within 19021904 between the supporters of union "neutrality" and those who advocated an open political intervention inside them. The debate was related to the process of creation of the Unión General de Trabajadores (General Workers Union). We aim to contribute to our knowledge about the tensions and disputes that shaped the Socialist Party at the turn of the century, and also to understand the peculiarities of the internal tension that would lead to the breakdown of the revolutionary syndicalists.
\end{abstract}

Key Words: Socialist Party - Unions - Syndicalism - Socialdemocracy

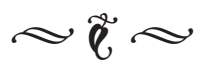

\section{Introducción}

Son conocidas las estrategias que cristalizaron, hacia la segunda década del siglo XX, en las principales corrientes del movimiento obrero argentino respecto al lugar de los gremios y la lucha sindical. Para los sindicalistas revolucionarios, los gremios eran el terreno auténtico de lucha de los trabajadores, y el único en el que estos debían desenvolver su actividad: este razonamiento continuaría en vigencia aun cuando su prédica fuera perdiendo, cada vez más, el segundo de los términos de su nombre, para anclarse en un más estrecho sindicalismo a secas. Un anarquismo ya en declinación seguía mientras tanto intentando combinar, a menudo con poco éxito, la acción en diversos grupos políticos con la intervención en gremios y federaciones a los que se buscaba nutrir de una abierta definición política libertaria. Los socialistas, por su parte, consideraban a los sindicatos como un tipo de organización que debía mantenerse neutral, sin posicionamientos políticos, en tanto esa tarea le estaba reservada al partido.

Juan B. Justo resumió esta postura en un trabajo de 1917, donde señaló que el Partido Socialista no debía "inmiscuirse en la organización gremial" sino limitarse a "servirla desde afuera, en cuanto a las leyes, el gobierno y la administración pública atañen a la organización gremial". ${ }^{1}$ Poco después, el XIV congreso del partido, realizado en Avellaneda en julio de 1918, refrendó esta orientación al votar una resolución sobre "la táctica y la doctrina socialista en materia gremial" en la que se planteaba que el "deber de todos los afiliados" era "pertenecer a sus respectivas organizaciones gremiales" y propiciar en ellas "el más absoluto alejamiento de toda tentativa de embanderar las organizaciones obreras en el 'comunismo anárquico', en el 'sindicalismo revolucionario' y en cualquier partido político, así como oponerse a realizar campañas

1. JUSTO, Juan Bautista, La organización obrera y el Partido Socialista, La Vanguardia, Buenos Aires, 1917. 
electorales a favor de cualquiera de estos". E1 vínculo entre los sindicatos, las cooperativas y el Partido Socialista debía "estar basado en la cordialidad, si es posible y necesario en la cooperación, pero nunca en la hostilidad y el sectarismo excluyentes". ${ }^{2}$

Pero esta formulación, que se convertiría en canónica, no se había alcanzado sin debates y tensiones: al igual que en otros países, la cuestión de las relaciones entre militancia política y sindical se convirtió desde un primer momento en motivo de discusión. En este contexto, este artículo se plantea una pregunta similar a la de una investigación pionera de María Cristina Tortti, quien sugería la necesidad de "efectuar un análisis retrospectivo que reconstruya el contradictorio proceso histórico a través del cual el Partido Socialista diseñó su estrategia gremial”, concentrándose en examinar las décadas de 1910 y $1920 .^{3}$ Más allá de los aportes de dicho trabajo elaborado a fines de los años ochenta, la relación establecida entre el PS y los sindicatos continuó "escasamente explorada por la historiografía y las ciencias sociales", tal como correctamente apuntó Ricardo Martínez Mazzola en un artículo que constituye una de las contribuciones más importantes para superar este campo de vacío historiográfico. ${ }^{4} \mathrm{En}$ efecto, este autor recordaba allí que la cuestión había sido

2. Citado en CAMARERO, Hernán y HERRERA, Carlos, El Partido Socialista en Argentina, Prometeo, Buenos Aires, 2005, p. 189.

3. TORTTI, María Cristina, Estrategia del Partido Socialista: reformismo politico y reformismo sindical, CEAL, Buenos Aires, 1989, p. 4.

4. MARTÍNEZ MAZZOLA, Ricardo, "La neutralidad como problema y como solución. La política gremial del Partido Socialista después de la ruptura sindicalista”, en Identidades, Comodoro Rivadavia, 2011, No 1, pp. 2-20. abordada más bien en torno a coyunturas específicas. $^{5} \mathrm{Su}$ artículo contribuyó a replantear los problemas presentados por Tortti pero en un período anterior al examinado por la autora, en particular el que se abrió luego de la ruptura de los sindicalistas.

En este trabajo, nuestro objetivo es llevar esa pesquisa aún más atrás en el tiempo, hacia los orígenes del siglo XX. La finalidad es analizar las tensiones internas que surgieron en el PS a propósito de la relación entre lucha económica y lucha política $y$, en particular, del problema de cómo actuar al interior de los gremios: rastreamos para ello un debate que se desenvolvió en los años 1902 a 1904 y enfrentó a los partidarios de la "neutralidad" en los sindicatos con aquellos defensores de una decidida intervención política en los mismos. El artículo apunta a contribuir a nuestro conocimiento sobre las disputas internas del Partido Socialista en el período crítico del cambio de siglo, así como a entender las particularidades de la tensión interna que llevaría a la ruptura de los sindicalistas revolucionarios.

5. Véanse, por ejemplo, BERTOLO, Maricel, Una propuesta gremial alternativa: el sindicalismo revolucionario (1904-1906), CEAL, Buenos Aires, 1993; BELKIN, Alejandro, Sobre los orígenes del sindicalismo revolucionario en Argentina, Ediciones del Centro Cultural de la Cooperación, Buenos Aires, 2007; CAMARERO, Hernán y SCHNEIDER, Alejandro, La polémica Penelón-Marotta (marxismo y sindicalismo soreliano, 19121918), CEAL, Buenos Aires, 1991; CAMARERO, Hernán, "Socialismo y movimiento sindical: una articulación débil. La COA y sus relaciones con el PS durante la década de 1920", en CAMARERO, Hernán y HERRERA, Carlos, El Partido Socialista..., Op. Cit. Ver también, para un período anterior al examinado en este trabajo, FALCÓN, Ricardo, "Lucha de tendencias en los primeros congresos del Partido Socialista Obrero Argentino, 1896-1900", en Apuntes para la bistoria del movimiento obrero y antimperialista latinoamericano, Ámsterdam, 1979, 1, pp. 58-84. 


\section{El vínculo entre partido y sindicato en la socialdemocracia internacional}

La cuestión de los vínculos entre los partidos y los sindicatos $-y$, más en general, entre militancia partidaria y militancia gremialatravesó los debates de los socialistas en todo el mundo desde fechas muy tempranas. Durante la década de 1890, la clave para los militantes de lo que globalmente podemos llamar el ala marxista y socialista del movimiento obrero internacional fue la diferenciación con el anarquismo: es por ello que el énfasis en la necesidad de la acción política se convirtió en la piedra de toque de toda delimitación de campos. Esto ocurría en momentos en que aparecían poco visibles los límites entre organizaciones gremiales y políticas: en los congresos participaban tanto partidos como organizaciones sindicales, y había una ambigüedad en torno a las implicancias de la aceptación de la "acción política" como requisito para participar.

En el segundo congreso internacional de la socialdemocracia, realizado en Bruselas en 1891, hubo un contrapunto entre la posición defendida por un sector de la delegación francesa, que defendía a las organizaciones sindicales como la principal herramienta de combate, enfatizando además la acción directa como la más efectiva forma de lucha, y la de los socialdemócratas alemanes, que planteaban su oposición a una organización internacional de sindicatos, consideraban que huelgas y boicots solo eran admisibles como "último recurso", y cuestionaban todo lo que implicase una autonomía de los gremios. Dos años más tarde, en Zurich, los socialistas alemanes insistieron en estos puntos de vista, subrayando la idea de "identidad de intereses entre el partido y los sindicatos". ${ }^{6}$ Sin embargo, este planteo volvió a encontrar resistencia y fue aprobada una moción que reiteraba la de Bruselas y llamaba a los trabajadores a organizarse en secretariados sindicales nacionales.

Recién en el congreso de Londres, realizado en 1896, se abordó explícitamente la cuestión de la relación entre sindicatos y partidos políticos y los planteos defendidos por la socialdemocracia alemana alcanzaron una consolidación. Se aprobó allí una resolución en los siguientes términos:

La lucha sindical de los trabajadores es indispensable para resistir la tiranía económica del capital, y por lo tanto mejorar su situación actual... Pero esta lucha económica no puede suprimir por completo la explotación capitalista, solo puede suavizarla... La organización de la clase obrera será incompleta e insuficiente mientras no esté organizada políticamente... Lo que sea que obtengan los trabajadores de los patrones en disputas abiertas debe ser confirmado por la ley para poder ser conservado, mientras que los conflictos sindicales pueden en otros casos ser innecesarios debido a medidas legislativas. $^{7}$

La síntesis de Londres aportó así un marco general para la acción de los socialistas, que caracterizaba a la organización sindical y la política como herramientas separadas y autónomas, pero vinculadas por el hecho de que una resultaba incompleta sin la

6. MILNER, Susan, The dilemmas of internationalism: French syndicalism and the international labour movement, 1900-1914, Berg, Nueva York, 1990, pp. 54 y 55.

7. Congres international socialiste des travailleurs et des chambres syndicales ouvrieres, Londres 26 juillet-2 aout 1896 [Reprint], Minkoff, Ginebra, 1980, p. 384. 
otra. Desde entonces, un punto de acuerdo para los militantes de la socialdemocracia internacional era, en primer lugar, que la lucha política - entendida en buena medida como lucha parlamentaria, en aquellos países donde eso era posible - constituía el eje fundamental de la actividad de los socialistas, y aquello que los diferenciaba de sus adversarios anarquistas; en segundo término, que la lucha económica también era necesaria y tarea de los sindicatos, en los cuales todo militante socialista debía intervenir.

Se trataba de una resolución lo suficientemente ambigua como para permitir interpretaciones diferentes por parte de quienes quisieran enfatizar más unos aspectos u otros del compromiso. Para el cambio de siglo, cuando el anarquismo ya estaba orgánicamente fuera de las reuniones de la internacional y se había alcanzado una relativa consolidación de los partidos socialistas, comenzaron a asomar a la superficie las discusiones que la resolución de Londres, en su formulación amplia, no había resuelto. ¿Cuál debía ser la relación entre ambas esferas, la política y la económica? ¿Tenían ambas la misma importancia o una dominaba sobre la otra? En relación con ello, ¿cuál debía ser la política de los socialistas al interior de los sindicatos? Este era el debate que estaba planteado en los primeros años de la década de 1900: como veremos, el socialismo argentino no estaba al margen de él.

\section{Los socialistas argentinos y la política gremial hacia el cambio de siglo}

En un primer momento, y en consonancia con lo que ocurría a nivel internacional, los socialistas de Argentina desarrollaron una actividad donde eran borrosos los límites entre organización gremial y política. El primer congreso de la primera Federación Obrera, realizado a mediados de 1891, resolvió designar una comisión encargada de formular "un programa análogo al de los partidos obreros europeos" y aprobó una resolución que se manifestaba en favor "de la abolición completa de la propiedad individual, en conformidad con todos los partidos de todos los países". ${ }^{8}$ El segundo congreso de la efímera federación, que se realizó en 1892 y sería también el último, establecía en el mismo sentido que "los privilegios de la burguesía capitalista" estaban asegurados "por el poder político", y por ello la respuesta del proletariado debía darse en el mismo terreno. ${ }^{9}$

La crisis y disolución de esta experiencia federativa, así como del periódico El Obrero que la acompañó, plantearon la necesidad de un balance que tomara en cuenta la necesidad de desarrollar en esferas independientes la actividad política y la económica. Es por ello que, en 1894 y 1895, los socialistas se plantearon la tarea de construir un nuevo intento de federación obrera - que terminaría nuevamente en un fracaso- mientras avanzaban decididamente en la fundación de un organismo político, en un proceso que tuvo un momento decisivo a mediados de 1896

8. Sobre la experiencia de la primera Federación Obrera, véanse, entre otros, ODDONE, Jacinto, Gremialismo proletario argentino, La Vanguardia, Buenos Aires, 1949, pp. 105-120; MAROTTA, Sebastián, El movimiento sindical argentino: su génesis y desarrollo, Lacio, Buenos Aires, 1960, pp. 99-102; POY, Lucas, Los orígenes de la clase obrera argentina, Imago Mundi, Buenos Aires, 2014, pp. 208-213.

9. POY, Lucas, Los orígenes de la clase obrera argentina..., Op. Cit. p. 212. 
con la realización del congreso constituyente del Partido Socialista. ${ }^{10}$ Luego de la derrota de la "huelga grande" de 1896 se abrió una etapa de reflujo en el movimiento obrero, que debilitó a las organizaciones gremiales y volvió a fojas cero los intentos de formar una federación de gremios. La convicción de los socialistas acerca de la necesidad de no confundir las esferas gremial y política, no obstante, no se había modificado, y al calor del ascenso huelguístico que llegó con el cambio de siglo, se plantearon nuevamente la tarea de promover una articulación de las diferentes sociedades de resistencia.

Desde fines de 1900, un conjunto de gremios vinculados estrechamente a la militancia de los socialistas emprendieron un nuevo intento de coordinar la acción de los gremios en una organización más amplia. En principio, el objetivo fue impulsar la publicación de un periódico que fuera "el órgano de las agrupaciones económicas": se tituló La Organización y apareció en enero de 1901, bajo la dirección del dirigente socialista Alfredo Pasqualetti. La iniciativa contaba con un claro aval del órgano oficial del partido, que recomendaba "a todos los trabajadores" hacer todo lo posible para difundirlo "en los talleres y fábricas". ${ }^{11}$ En las semanas siguientes se avanzó un paso más, y se realizaron reuniones para que esta coordinación fuera más allá de una publicación y tomara forma orgánica, convocando a un congreso gremial. Después de varios meses de preparativos, este se realizó en mayo de 1901 y dio como resultado la fundación de la Federación Obrera Argentina: si bien no era la primera vez que se creaba una organización de estas

10. Ídem, pp. 213-223.

11. Véase La Vanguardia, Buenos Aires, 22 y 29/12/1900. características, incluso con el mismo nombre, sí representaba la primera ocasión en la que reflejaba un compromiso entre militantes socialistas y anarquistas. ${ }^{12}$

Lo que nos interesa destacar aquí es que, más allá de este compromiso coyuntural, toda la iniciativa estaba marcada por una doble tensión subyacente. En primer lugar, una entre socialistas y anarquistas. Aun desde antes del congreso, la idea de fundar una federación había sido recibida con recelo por el grupo que publicaba La Organización, que en abril de 1901 se preguntaba si "algo positivamente práctico que pudiera reportar beneficios inmediatos a la clase obrera" podía surgir de un congreso..$^{13}$ Las tensiones se pusieron de manifiesto en el congreso y se profundizaron inmediatamente después del mismo: la evidencia más clara fue la decisión de un conjunto de gremios de seguir publicando el periódico, a pesar de que, según las resoluciones, este debía desaparecer para dar paso a otro llamado La Organización Obrera.

Desde mediados de 1901, en efecto, coexistieron ambos periódicos, cuyas diferentes orientaciones servían como polos para reagrupar a las sociedades gremiales según su mayor afinidad con los planteamientos socialistas o anarquistas. Si bien La Organización seguía presentándose como un órgano estrictamente gremial, era caracterizado por sus adversarios como un periódico orientado por militantes socialistas.

12. Sobre la fundación de la FOA, véanse, entre otros, MAROTTA, Sebastián, El movimiento sindical..., Op. Cit., pp. 122-135; ODDONE, Jacinto, Gremialismo proletario argentino..., Op. Cit., pp. 134-140.

13. Citado en MAROTTA, Sebastián, El movimiento sindical..., Op. Cit., pp. 105-106. 
El Obrero, órgano de los panaderos, se refería a él como "el periódico que pagan entre varias sociedades de resistencia (i?) y escrito por los partidarios de Marx". ${ }^{14}$ Los editores de La Organización a lo largo de este período eran, en efecto, militantes socialistas: además de Pasqualetti, se desempeñaron en esa tarea otros cuadros del partido como Luis Boffi, Emilio Ferrando y Pedro Barsanti.

Las tensiones también se desarrollaban, de todas formas, en un segundo nivel: al interior del propio socialismo. En efecto, la frágil unidad de la F.O.A. se mantuvo con dificultades en la segunda mitad de 1901 y los primeros meses del año siguiente, pero el núcleo impulsor de La Organización no solo continuaba con la publicación de su periódico sino que exploraba la posibilidad de crear un "comité de propaganda gremial", lo cual implicaba darle forma organizativa al espacio editor del periódico y, en los hechos, romper con la federación. Esta iniciativa era cuestionada por el periódico oficial del partido, que a comienzos de 1902 se manifestó a favor de que los gremios editores de La Organización se mantuvieran dentro de la F.O.A. Otra evidencia de estas diferencias internas entre militantes socialistas es la firma de Francisco Cúneo, junto a otros importantes dirigentes gremiales de orientación anarquista, en el comunicado de la F.O.A. que repudiaba la iniciativa de crear un comité paralelo. ${ }^{15}$

En cualquier caso, la ruptura no avanzó y todos los sectores participaron del segundo

14. "Ante todo la verdad", El Obrero, Buenos Aires, 18/5/1901.

15. ODDONE, Jacinto, Gremialismo proletario argentino..., Op. Cit., p. 190. congreso de la federación, en 1902. Pero se trataba solamente de una postergación: la primera de las líneas de tensión señaladas, aquella entre socialistas y anarquistas, resultaba demasiado aguda y el segundo congreso terminó de consumar la ruptura, que formalmente se debió a un debate sobre acreditación de delegados pero que expresaba la imposibilidad que tenían las dos tendencias de coexistir en una misma organización que en realidad impulsaban por diferentes motivos: unos para impulsar la huelga general, los otros para evitarla. Pocos meses más tarde, la huelga de noviembre de 1902 confirmó esta divergencia de orientaciones $y$, a su turno, reforzó aún más las diferencias. ${ }^{16}$

Después de la huelga, la segunda línea de tensión pareció desaparecer, en tanto la postura de los socialistas se unificó en torno a la necesidad de avanzar en una clara diferenciación con los anarquistas. El impulso al Comité de Propaganda Gremial, en primer término, planteaba la necesidad de crear una federación paralela a la F.O.A., cuyo nombre, Unión General de Trabajadores, en sintonía con el ejemplo español, parece haber sido indiscutible desde el primer momento. En esta etapa, la perspectiva de los socialistas no era que la nueva federación coexistiera con la F.O.A., sino que lograra desplazarla. A mediados de diciembre de 1902, La Vanguardia lamentaba "el desastre inmerecido a que han llevado a la organización obrera en el país los charlatanes que pregonan el sanalotodo de la huelga general" y caracterizaba que "lo que ya existía ha quedado poco menos que deshechos". La conclusión era que debía

16. Véase POY, Lucas, "E1 Partido Socialista y las huelgas: una relación incómoda", Archivos de historia del movimiento obrero y la izquierda, Buenos Aires, 2015, No 6, pp. 31-51. 
darse la espalda a la federación creada el año anterior y desarrollar un organismo nuevo: "la Federación Obrera que, como tal, solo fue un antro de gimnasia revolucionaria (de frase, se entiende) que llegó a los resultados conocidos, ha fracasado definitivamente" ${ }^{17}$

Este acuerdo general, no obstante, encubría nuevamente una tensión interna, que esta vez se iba a desenvolver en forma abierta. Lo que estaba en cuestión ya no era la viabilidad o no de un frente único con los anarquistas para construir una única federación gremial. Ahora la discusión giraba en torno a la postura que debían tomar los militantes socialistas en los gremios y en la recién formada unión. ¿Cuánto de “política” debía haber en ellos?

\section{La crítica a la "neutralidad" en los sindicatos}

El 24 de enero de 1903, La Vanguardia publicó un artículo de Luis Boffi que anticipaba los términos del debate. El autor criticaba explícitamente la postura de quienes llamaba "los compañeros neutrales", según la cual los socialistas debían evitar desenvolver en los sindicatos una abierta prédica política. En efecto, el artículo consideraba que los socialistas habían adoptado "un criterio neutral y un espíritu completamente trade unionista" con el objetivo de "evitar dentro de las sociedades gremiales, esa lucha intestina de diversas tendencias". La consecuencia era que se habían batido "en una especie de retirada alentando a los contrarios a que continuaran diciendo 'no queremos política", mientras los supuestos adversarios de la lucha

17. "Necesidad de un congreso obrero", La Vanguardia, Buenos Aires, 13/12/1902. política, a su entender, "no hacían sino una política de la peor especie ayudados por una parte de los obreros inconscientes y de la otra por el silencio de los socialistas".

El artículo planteaba en forma explícita que la posición "neutralista" era el resultado de una adaptación a una presión sufrida en la militancia gremial: Boffi admitía que una línea más "política" en los sindicatos podía reducir su predicamento entre los obreros. Argumentaba, sin embargo, que eso se vería compensado por un enriquecimiento cualitativo de la actividad socialista. En su opinión, si los socialistas "hubieran hecho efectivamente la propaganda sectaria de su táctica, tal vez en cantidad el número de obreros organizados sería menor al actual, pero en calidad mucho mejor". Para defender su posición, que sabía minoritaria entre los dirigentes del partido que tenían responsabilidades en la UGT, Boffi se apoyaba en los planteos de los socialistas europeos. Además de mencionar los casos español, belga y danés, se apoyaba por supuesto en el ejemplo de Alemania, donde "la mayor parte de las sociedades gremiales participan en las elecciones invitando a sus asociados a votar por los candidatos socialistas". ${ }^{18}$

Boffi no estaba solo en la defensa de estas posturas. En una nota aparecida a mediados de febrero, Adrián Patroni desenvolvía una crítica al posicionamiento "neutralista": "apoyar calurosamente la organización gremial", argumentaba, no debía "confundirse con mantenerse prescindentes dentro de las sociedades de resistencia”. Para Patroni, en los gremios, "como en todas partes", los

18. BOFFI, Luis, "Acción socialista en las sociedades gremiales”, La Vanguardia, Buenos Aires, 24/1/1903. 
militantes del partido debían "ser socialistas, proceder como socialistas, y difundir las convicciones que como tales tenemos". ${ }^{19}$

Ese mismo mes, el debate se expresó en otro órgano de prensa, El Progreso de la Boca, un periódico barrial de orientación progresista y afín al movimiento obrero y al PS, que en ese momento era dirigido por el socialista Zaccagnini. Fue él mismo quien, el 15 de febrero, publicó una nota en la que abordaba el problema. Zaccagnini también partía de caracterizar que la huelga general del año anterior debía dejar enseñanzas en la táctica socialista. En su caso, entendía que el balance debía orientarse a un cuestionamiento de la política de neutralismo en las sociedades gremiales. Para el director del periódico boquense, "el tiempo del corporatismo puro y sencillo" se había agotado. Al igual que Boffi, Zaccagnini criticaba lo que entendía como una postura defensiva de los socialistas, que había llevado a un crecimiento de sus adversarios anarquistas. Desde su punto de vista, no podía recriminarse la actitud de los ácratas en la FOA. En todo caso debía ser criticada la actitud de los propios socialistas, que no habían cumplido con el "deber elemental" de desarrollar sus posiciones políticas en los sindicatos, dejando así "el campo libre a los adversarios para que se despacharan a su antojo".

A diferencia de la posición expresada en el periódico partidario, Zaccagnini lamentaba la división de la federación. Su postura era favorable a la acción conjunta en un mismo organismo obrero, pero desenvolviendo abiertamente los posicionamientos políticos

19. PATRONI, Adrián, "Los socialistas en las sociedades gremiales”, La Vanguardia, Buenos Aires, 14/2/1903. socialistas. "Debíamos y podíamos", sostenía, "entrar en el fuerte mismo del adversario, para defendernos, para desvirtuar las afirmaciones erróneas, inciertas, falsas...; debíamos luchar frente a frente con los adversarios". Zaccagnini era así el único de los participantes en el debate que combinaba una crítica del "neutralismo" con una apelación a la acción conjunta, en los sindicatos, con los adversarios del partido. Caracterizaba que la división del movimiento obrero era negativa y hacía "el juego de los poderosos": las diferencias de táctica indiscutiblemente existían, pero los socialistas debían "tener valor y constancia bastantes para aprender a discutir serena y tranquilamente las cuestiones que nos atañen con nuestros mismos compañeros de causa, de cualesquiera escuela político-económica y religiosa”. ${ }^{20}$

\section{La cuestión política en el primer congreso de la UGT}

En marzo de 1903, finalmente tuvo lugar el congreso fundacional de la Unión General de Trabajadores. En sus votaciones, tanto las unánimes como las que dieron lugar a un debate, el congreso reflejó aquellos ejes en los que había acuerdo pero también los debates y tensiones que recorrían a la militancia socialista en cuanto a la táctica que debía adoptarse al interior de los gremios.

Había una serie de rasgos que contaban con acuerdo general. La organización de los diferentes gremios debía tener como objetivo fomentar la propaganda y estimular la

20. ZACCAGNINI, Antonio, "Una opinión sobre el congreso gremial”, El Progreso de la Boca, Buenos Aires, 15/2/1903. 
organización en pro de reformas económicas, para evitar así desórdenes y acciones radicalizadas que pudieran poner en riesgo lo conseguido por el movimiento obrero. Según Luis Poggi, que dio el informe inicial, "la acción revolucionaria de la organización debe circunscribirse actualmente a la consecución de mejoras que, reduciendo poco a poco la esclavitud económica de los obreros, vaya haciendo posible su liberación moral e intelectual, política y social". Los militantes de la nueva unión eran "decididos y francos adversarios de una 'gimnasia revolucionaria' que solo procura golpes, $y$ francos y decididos partidarios de las reformas". ${ }^{21}$

Pero más allá de estos acuerdos generales se plantearon una serie de debates, que en buena medida expresaban las líneas de tensión que venían desarrollándose previamente. Según La Vanguardia, la discusión sobre la cuestión de la huelga general provocó "una animada discusión” y se presentaron diferentes mociones que finalmente quedaron resumidas en dos. Una moción de los panaderos de Córdoba proponía rechazar en forma absoluta este método de lucha y planteaba que, "dadas las condiciones de organización gremial actual en la clase obrera de la Argentina", el congreso debía considerar "prematura toda declaración favorable a la huelga general". La moción que finalmente fue aprobada, presentada por Mantecón, introducía sin embargo una serie de matices y consideraba que la huelga general podía "ser útil en cuestiones que afecten diariamente al pueblo trabajador y como acto de resistencia y de protesta" y "un medio de lucha eficaz cuando [fuera] declarada contando con una previa

21. “Congreso obrero gremial”, La Vanguardia, Buenos Aires, 7/3/1903. organización que ofrezca probabilidades de triunfo", aclarando sin embargo que rechazaba "en absoluto la huelga general toda vez que sea intentada con fines de violencia y revuelta”. ${ }^{22}$

El otro debate de fondo que se planteó en el primer congreso fue el que se dio en torno a la cuestión de la "legislación obrera", y fue allí donde se pusieron de relieve, de un modo más claro, las tensiones entre los "neutralistas" y los "políticos", obteniendo la mayoría los primeros. El tema generaba expectativa: según la crónica de La Vanguardia, "la numerosa barra... esperaba con marcada impaciencia que el congreso abocara esta materia". Hubo numerosas intervenciones, que fueron refundidas por la mesa en dos mociones. Una, firmada por Adrián Patroni, recomendaba "a la clase trabajadora que independientemente de la lucha gremial los obreros se preocupen de la lucha política y conquisten leyes protectoras del trabajo dando sus votos a los partidos que tienen en sus programas reformas concretas, en pro de la legislación obrera”. En oposición a ella, una moción suscripta por Basilio Vidal, Domingo de Armas y Alfredo Torcelli, que fue finalmente aprobada, evitaba cualquier mención explícita a los partidos políticos y se limitaba a recomendar a los sindicatos la tarea de "recabar, gestionar o tramitar de los poderes públicos por los medios al alcance de la clase trabajadora, leyes que favorezcan los intereses del trabajo". ${ }^{23}$

También se puso de relieve la cuestión del vínculo entre lucha política y económica en torno a los debates sobre las celebraciones del $1^{\circ}$ de mayo. Una primera proposición planteó

22. Ibídem.

23. Ibídem. 
que las mismas debían ser organizadas conjuntamente por la UGT y el PS, pero en la quinta sesión surgieron planteos que señalaban que el día "debía ser solemnizado independientemente por la UGT para quitar a la manifestación todo carácter político". La votación fue reconsiderada y se aprobó una moción que no hacía ninguna mención explícita al PS. Se votó también una moción que recordaba que la UGT había declarado y persistía en declarar "que no pertenece a partido político alguno, ni preside sus deliberaciones ningún espíritu partidista”. ${ }^{24}$

En suma, en la naciente UGT dominaba indiscutiblemente la postura que había caracterizado a los socialistas respecto a la cuestión de la organización obrera y las huelgas en el período anterior: se planteaba la necesidad de fomentar la propaganda y estimular la organización "pacífica y ordenada", con el objetivo de obtener mejoras económicas, rechazando la violencia y la "gimnasia revolucionaria". Había un sector, que resultó mayoritario en el congreso, que admitía considerar la utilidad de la huelga general - siempre que contara con una adecuada preparación y garantías de éxito-para obtener algunas reivindicaciones concretas. El mismo sector mayoritario, no obstante, se preocupó por definir una serie de limitaciones estrictas, de tipo reglamentario, para evitar la generalización de conflictos huelguísticos que no contaran con la suficiente preparación. En conjunto, el espíritu de las resoluciones estaba siempre dentro de los marcos de los matices discutidos en la socialdemocracia internacional de la época y expresaba, en buena medida, el predominio

24. “Congreso obrero gremial”, La Vanguardia, Buenos Aires, 21/3/1903. de los grupos de obreros más calificados, que eran los que podían llevar adelante las huelgas parciales y que al mismo tiempo pagaban gravosas consecuencias si se sumaban a un movimiento mal preparado.

E1 congreso reflejó asimismo, de todas formas, la tensión que subyacía en cuanto al problema de la posición que debían adoptar las sociedades gremiales frente a la lucha política. La postura que encontró eco mayoritario fue aquella que defendía la mayor autonomía de las organizaciones obreras, y se oponía a presionar para que éstas adoptasen posicionamientos políticos. Se trata de la posición que venía siendo cuestionada, como vimos, en la prensa partidaria: es importante destacar, sin embargo, que fue defendida en el congreso por cuadros dirigentes del partido, como Torcelli, de Armas y Vidal. Significativamente, fueron los mismos dirigentes que argumentaron en favor de una reglamentación estricta acerca de cuándo y cómo debían ser convocadas las huelgas, mostrando que se trataba de una posición de corte obrerista, pero no necesariamente afín a las huelgas en general.

\section{Defender la lucha política: ¿ir “contra la corriente?"}

Luego de las definiciones del congreso, la polémica continuó en las publicaciones socialistas. La editorial de La Vanguardia del 21 de marzo de 1903 estaba escrita por Juan Sanguinetti y volvía a defender la orientación "política", planteando una tensión con lo resuelto en el congreso y con la orientación desplegada en él por otros importantes dirigentes partidarios. Para Sanguinetti, 
era "necesario cambiar de táctica: dar a la organización obrera un espíritu marcado de lucha de clases, despojarla de ese espíritu estrecho, neutrale incoloro que las caracteriza". Nuevamente, se planteaba que desenvolver esta posición implicaba enfrentarse a una serie de prejuicios y reticencias reinantes en las filas obreras. Sanguinetti reconocía que, "al dirigir el movimiento obrero por este camino tendremos que luchar con muchos obstáculos, tendremos que luchar contra la corriente".

El artículo dejaba en evidencia, además, que la cuestión era discutida en las filas socialistas, y que muchos militantes que decían coincidir con esta perspectiva se encontraban en la práctica desarrollando una táctica distinta debido a las presiones de la actividad cotidiana. Según Sanguinetti, "muchos socialistas manuales están, en teoría, de acuerdo con esto, pero en la práctica la cosa cambia”. Estos militantes, decía, "objetan que el momento no es oportuno, que eso vendrá por sí solo, que ese rumbo puede traer como consecuencia un desbande". Para el autor de la editorial, se trataba de un error que debía ser remediado, pues de nada servía "un proletariado numeroso si éste es falso de ideales, si no está poseído de una conciencia de clase clara y bien determinada". ${ }^{25}$

El mismo argumento era retomado en un artículo publicado por Esteban Dagnino apenas una semana más tarde. Allí se consideraba que las posiciones que expresaba Sanguinetti eran las mismas que "en materia de organización obrera tenemos la mayoría de los que militamos en el partido": su mérito había sido, no obstante, "haber tenido la

25. SANGUINETTI, Juan, "Acción de los socialistas", La Vanguardia, Buenos Aires, 21/3/1903. suficiente franqueza de declarar abiertamente en forma neta y concisa, lo que sotto voce decimos muchos, sin atrevernos a romper una vez por todas con las preocupaciones y los criterios dominantes que nos impiden apartarnos de la vieja rutina”. Dagnino reconocía que esta campaña para promover la acción política encontraría obstáculos, basados en los prejuicios existentes en la clase obrera al respecto. "Sabemos", decía, "que ha de costar trabajo arrancar de los cerebros el prejuicio añejo que hace considerar a la política como el cuco". ${ }^{26}$

En esa primera mitad de 1903, en suma, las notas publicadas en La Vanguardia mostraban en forma consistente una defensa de la línea crítica de la "neutralidad". Para encontrar la argumentación de los defensores del "neutralismo" debemos dirigir nuestra atención a una conferencia dictada por Alfredo Torcelli en el salón Vorwärts, el 21 de mayo de ese año. La misma, titulada "Organización gremial", fue editada como folleto y distribuida por la propia UGT: el texto de la misma no apareció en $L a$ Vanguardia, aunque el periódico partidario sí publicó, en un par de ocasiones, un pequeño recuadro que anunciaba la salida del folleto.

La conferencia apuntaba a un público sindical, y tenía como objetivo abordar los problemas que debían ser superados para poder consolidar asociaciones de resistencia. De hecho, Torcelli comenzaba haciendo referencia a las dificultades que enfrentaba la organización gremial en el país debido a la heterogeneidad de su clase obrera. Donde fuera que hubiera tres personas, decía, habría

26. DAGNINO, Esteban, "El cuco", La Vanguardia, Buenos Aires, 28/3/1903. 
"posiblemente tres idiomas, tres costumbres, y urgiendo mucho el caso, quizá tres antagonismos". Desde su punto de vista, las divisiones entre los trabajadores obedecían al peso de la "mentira patriótica", la "mentira religiosa" y la "mentira económica", en tanto cuestiones de nacionalidad, de religión o de afinidad con los patrones podían obstaculizar la acción colectiva de los trabajadores como clase. Su argumento, en este contexto, era que había que evitar que estas tensiones fueran un factor de división, con un planteo que de todas formas sugería una cierta adaptación a ellas: "orillar estos inconvenientes", recomendaba, "suavizar sus asperezas, evitar las discusiones que provocan y acaban por eliminarlos, tal es la ardua y benéfica tarea" que debía plantearse quien quisiera contribuir a la organización obrera.

Según Torcelli, quienes pretendían "destruir en un día, de buenas a primeras, el aplastante lote de prejuicios y preconceptos, de cariños y desconfianzas que carga cada individuo, o no proceden de buena fe con fines inconfesables o proceden de buena fe sin preparación para la obra”. En ambos casos su actitud era "dañosa" y debía evitarse. El corolario de este razonamiento era la necesidad de no introducir la política en la actividad gremial: el neutralismo era la única garantía para poder conciliar las diferencias y prejuicios que existían en las filas obreras. Las sociedades gremiales debían "organizarse para la lucha de clases, para el mejoramiento económico inmediato de sus miembros, para la ayuda mutua en caso de accidentes o fallecimiento y para nada más". Los sindicatos debían tener como base el cosmopolitismo y ser un campo común para trabajadores de diferentes tendencias.
En todo momento se advierte en el planteo de Torcelli la experiencia de quienes intentaban abrirse un camino organizativo en la clase obrera, enfrentando prejuicios, desconfianzas y suspicacias en las filas de los trabajadores. El "neutralismo" era la conclusión a la que lo llevaba su búsqueda de adaptarse de algún modo a estas dificultades. Torcelli advertía correctamente la necesidad de unificar a la clase más allá de sus diferencias políticas, nacionales o religiosas, pero iba un paso más lejos y llamaba a evitar incluso la introducción de polémicas y debates en las filas obreras. La restricción a la actividad política debía quedar incluida, según Torcelli, en las propias normas estatutarias de las sociedades gremiales, las cuales deberían "prescribir terminantemente que en los actos sociales" quedasen "prohibidas en absoluto todas las cuestiones que no sean las que se refieren a la jornada y al salario del trabajo y a los temas que de ellas se derivan en el terreno práctico de la lucha de clases". ${ }^{27}$

La respuesta a Torcelli no se hizo a esperar, y apareció en las páginas de La Vanguardia con una serie de cuatro artículos a cargo de Bartolomé Bosio. Quien sería apenas unos años más tarde uno de los principales referentes del sindicalismo revolucionario, salió a la palestra en este debate para cuestionar la orientación dominante entre los dirigentes sindicales del partido, defendiendo la postura favorable a desenvolver una abierta actividad política en los gremios. La serie comenzó a aparecer el 13 de junio, y en ellos caracterizaba la posición de Torcelli y "los compañeros neutrales" como "corporativista o reformista"

27. TORCELLI, Alfredo, Organización gremial, Unión General de Trabajadores, Buenos Aires, 1903. 
y la catalogaba como dominante en la UGT. Según Bosio, los socialistas debían "combatir enérgicamente" esta tendencia. La tarea era "atraer a la masa obrera con principios bien claros; encarrilarla en la lucha de clases y desviarla de aquellos caminos que la alejan de ella". Los socialistas no debían ni podían "favorecer su agrupamiento con el único objeto de las mejoras inmediatas": hacerlo implicaría mostrarse "inconsecuentes con nuestros principios y con nosotros mismos", así como revestirse "de una dualidad que tampoco debemos ni podemos consentir".

Como otros antes que él, Bosio volvía a admitir que la posición de su adversario era la que mejor se adaptaba a prejuicios y reticencias habituales en las filas obreras: era una táctica, sin embargo, que traía consecuencias extremadamente negativas. "E1 método corporativista", planteaba, "tiene el inconveniente gravísimo de adaptarse a la ceguera natural de las masas (que no advierten más que la explotación directa patronal) y estimularla". Ponía explícitamente de manifiesto la existencia de esa presión, proveniente de las filas obreras, y la adaptación de muchos socialistas a ella: llamaba a "combatir la inconsecuencia de los compañeros que siendo socialistas y procediendo como tales en todas partes menos en los gremios concurren a agravar la corriente que proclama la neutralidad en las asociaciones económicas". Más adelante, al referirse a "los argumentos que nos salen al encuentro para demostrarnos la abstención de toda propaganda política y socialista", Bosio abordaba las presiones que existían en amplios sectores de la clase obrera para impulsar una postura "apolítica":
Se dice: que los trabajadores, al oír esas consideraciones, que antes hemos referido, se espantan, porque eso es política; que, como consecuencia se suceden disturbios... y que con esa propaganda se desnaturaliza el carácter de las organizaciones obreras. ${ }^{28}$

A su turno, asumía que muchos militantes consideraban que la política era "el terror de los trabajadores" y que hablar de ella equivalía "a querer la disolución del gremio". Para Bosio, eso se debía al carácter que tomaba la política en el país y que llevaba a los trabajadores a mirarla con recelo: "las causas de que el obrero desconfíe de la política”, argumentaba, eran que no había "comprendido lo que significa política; que si alguna vez ha participado de la lucha política, lo ha hecho sin conciencia de proletario; ha apoyado indistintamente a éste o aquel partido y generalmente se ha dejado guiar por la simpatía hacia éste o aquel personaje”. Retomando argumentos muy habituales en el socialismo local de la época, Bosio advertía que el dominio de la "política criolla" y sus fraudes era responsable de esos prejuicios. Muchos obreros habían "concurrido a la política... y se [habían] prestado a una infinidad de farsas". Los resultados habían sido "nulos y malos": como consecuencia, el obrero "se descorazona; abandona toda participación y se hace desconfiado y rebelde". Para Bosio, la propaganda puramente gremial tenía el grave problema de profundizar estos prejuicios y no formar una conciencia de clase, sino una puramente corporativa. ${ }^{29}$

28. BOSIO, Bartolomé, "Los socialistas y la organización económica”, La Vanguardia, Buenos Aires, 13/6/1903.

29. BOSIO, Bartolomé, “Los socialistas y la organización 
En el tercer artículo de la serie Bosio se refería al argumento desenvuelto por "los compañeros neutrales”, según el cual la conquista de ciertas mejoras inmediatas contribuía a la formación gradual de una conciencia de clase. Para Bosio, sin embargo, esta lucha por las mejoras debía estar siempre vinculada al "objetivo general". Llegaba así bastante lejos, hasta problematizar la cuestión de los límites de la conciencia puramente económica y la necesidad de una propaganda socialista para superarla:

Los proletarios sienten su condición de explotados, el antagonismo de clases, la imposición del Estado, etc. pero ellos no alcanzan a comprender el mecanismo, y es justamente aquí en donde interviene y es eficaz la propaganda socialista (folletos, conferencias, conversaciones, etc.). ${ }^{30}$

En la cuarta y última entrega, acusaba a Torcelli y a los "neutrales" de preocuparse únicamente por "el número, el agrupamiento a toda costa" y no por la construcción sólida de un gremio a través de "la formación de la conciencia de clase". Quien sería uno de los principales referentes de la tendencia sindicalista revolucionaria advertía, apenas unos pocos años antes, que el "el método corporativista crea ilusiones sobre el alcance de la lucha gremial", en tanto "el obrero se acostumbra a ver en él la panacea de todos los males sociales; a considerar la huelga como el arma non plus ultra (cuando en realidad los resultados que ella da son de

económica" (segunda entrega), La Vanguardia, Buenos Aires, 20/6/1903.

30. BOSIO, Bartolomé, "Los socialistas y la organización económica” (tercera entrega), La Vanguardia, Buenos Aires, 27/6/1903. relativa eficacia) y por lo tanto a hacer de ella un uso inmoderado, lo cual equivale a sufrir frecuentes derrotas que perjudican enormemente a la organización”. ${ }^{31}$

\section{El cierre del debate en 1904}

El debate tuvo una última expresión en los primeros meses de 1904. E1 6 de enero, una masiva asamblea socialista de la capital, que según La Vanguardia contó con la participación de más de 500 personas, discutió la cuestión de la postura a adoptar por el partido ante las sociedades gremiales y las luchas económicas. El tono general del debate $\mathrm{y}$ las resoluciones fue favorable a asegurar la intervención de todos los militantes partidarios en sus respectivas sociedades. Una de las resoluciones declaraba que "la acción de los socialistas en los gremios" era un asunto de "suma importancia" que debía "debatirse en la prensa del partido para poder tomar una determinación reflexiva". ${ }^{32}$

En efecto, la cuestión abrió una serie de debates en La Vanguardia. El principal fue el que se planteó entre Enrique Dickmann y Adrián Patroni, una polémica analizada hace algunos años en un trabajo de Alejandro Belkin. ${ }^{33}$ En forma simultánea, de todos modos, se produjeron otras intervenciones

31. BOSIO, Bartolomé, "Los socialistas y la organización económica" (cuarta entrega), La Vanguardia, Buenos Aires, 4/7/1903.

32. "Asamblea local”, La Vanguardia, Buenos Aires, 16/1/1904.

33. BELKIN, Alejandro, "El debate Patroni-Dickmann (1904). Partido y sindicatos en el socialismo argentino", ponencia presentada en XI Jornadas Interescuelas de Historia, Tucumán, 2007. 
que continuaban en la línea del debate del año previo. El 20 de febrero, por caso, apareció un artículo de Ernesto Piot con el título "Los socialistas en las sociedades gremiales". La misma resulta interesante porque Piot sería, junto con Bosio y otros dirigentes, uno de los principales referentes del sindicalismo revolucionario. A diferencia de Bosio, no obstante, Piot se alineaba claramente en la posición "neutralista": los socialistas debían "necesariamente encarar los asuntos que en las sociedades gremiales se discute con criterio eminentemente socialista, pero de ninguna manera debemos hacer socialismo en las sociedades gremiales". Según Piot, en el seno de los gremios no debía discutirse nada que no se vinculara con "el mejoramiento económico inmediato de sus miembros". E1 método y las ideas socialistas debían "inculcarse" en la clase obrera "pero no en el seno de las sociedades gremiales, porque haciéndolo solo produciremos dispersiones". ${ }^{34}$

La respuesta vino en este caso de Guido A. Cartey, en un artículo publicado el 27 de febrero. Sostenía que Piot cometía un "un gravísimo error" en tanto el movimiento obrero debía expresarse "en ambos terrenos [gremial y político], y en consecuencia la organización gremial de los trabajadores no puede a menos de ajustarse a los fines del colectivismo". Cartey volvía a defender la tesis "política": en su opinión, no era posible hacer "socialismo por un lado y corporativismo por otro; sería, sencillamente, masturbar el movimiento obrero". Las sociedades gremiales, desde su punto de vista, debían ser "escuelas de educación política de los trabajadores”, en tanto la lucha gremial era "en sí insuficiente

34. PIOT, Ernesto, "Los socialistas en las sociedades gremiales”, La Vanguardia, Buenos Aires, 20/2/1904. para proveer a los mismos trabajadores de los elementos con los cuales han de elaborar su redención económica". También admitía que la táctica neutralista se adaptaba mejor a las tendencias del movimiento obrero: "hacer lo que dice Piot es mucho más fácil y la organización de los trabajadores en el terreno gremial produce por lo que a cantidad de trabajadores se refiere, mejores resultados inmediatos". Pero era un camino que llevaba "a un verdadero desastre por cuanto a la conciencia de los mismos y el contingente de fuerza real que pueden proporcionar en las luchas contra el capitalismo". Esto se debía a que el camino del neutralismo sindical llevaba a reforzar, antes que a doblegar, las reticencias de los trabajadores respecto a la prédica socialista. Concluía con una caracterización que tenía algo de profética: "una vez que esos trabajadores se han convencido fácilmente de la necesidad de organizarse para la ayuda mutua y las mejoras inmediatas, son completamente refractarios a las ideas de un movimiento obrero que se inspire en la lucha de clases que no conocen". ${ }^{35}$

Algunas semanas más tarde, en las elecciones legislativas de la ciudad de Buenos Aires, el Partido Socialista consiguió su primer gran triunfo con la elección de Alfredo Palacios como diputado por la cuarta sección. La conquista parlamentaria tendría un profundo impacto para el partido, en una serie importante de aspectos: uno de ellos fue que implicó el cierre de hecho del debate que reconstruimos en este trabajo, del cual ya no volvieron a aparecer referencias en $L a$ Vanguardia.

35. CARTEY, Guido A., "Los socialistas en las sociedades gremiales", La Vanguardia, Buenos Aires, 27/2/1904 (Firmado como "Oferfla G. Yetrac"). 
Hacia fines de 1904 y comienzos de 1905, el debate ya no se plantearía tanto entre "neutralistas" y "políticos" sino entre quienes miraban con recelo el desenvolvimiento de los gremios y de la UGT y quienes se afirmaban en ellos. Iba surgiendo así una tensión interna entre los que militaban en los gremios y los que no lo hacían, aunque no siempre se manifestase como una diferencia política. Había, por supuesto, una línea comunicante entre ambas discusiones, en la medida en que la insistencia en mantener la "neutralidad" en los gremios corría el riesgo de llevar a una autonomía de los mismos: el paso siguiente podía ser, y lo fue en muchos casos, plantear que no era necesario complementar su desarrollo con la actividad del partido. Al mismo tiempo, es importante observar las diferencias: el planteo de los socialistas partidarios de la "neutralidad" defendía en todo momento la actividad política del partido y en eso se diferenciaba claramente de los planteos posteriores de los sindicalistas. Al mismo tiempo, como hemos visto, los principales defensores de las tesis "neutrales"-como Vidal, De Armas o Torcelli- eran dirigentes que se mantendrían en el campo del partido, mientras que un referente como Bosio, sólido defensor de las posturas "políticas", terminaría siendo dirigente del sindicalismo revolucionario.

\section{Conclusión}

En buena medida reconstruir la historia del Partido Socialista argentino implica recuperar los debates que se desenvolvieron a lo largo de su historia y quedaron, la mayor parte de las veces, obturados en las interpretaciones elaboradas por la historiografía del propio partido, más preocupada por subrayar la continuidad de una tradición que las discusiones y crisis periódicas a través de las cuales esa trayectoria se fue configurando. En este trabajo hemos analizado un debate virtualmente ignorado por la historiografía previa: el que se planteó en los años 1903 y 1904 entre los partidarios de la "neutralidad" en el terreno sindical y aquellos que proponían desenvolver en los gremios una abierta propaganda política. Este debate se insertaba, en primer lugar, en el marco más general de la socialdemocracia internacional: la reconstrucción de esta discusión en las páginas del periódico socialista argentino muestra que los militantes locales no eran ajenos a una polémica que, en esos años, recorría al mundo socialista y ocuparía un importante lugar en el congreso de Stuttgart en 1907.

Pero además, en segundo término, es preciso ubicar esta discusión en el contexto específico de desarrollo del socialismo argentino. Este artículo ha intentado echar luz sobre un debate que se desarrolló inmediatamente antes de que cristalizara la tendencia sindicalista revolucionaria, y después de que se reincorporaran al partido los disidentes "colectivistas" que habían protagonizado una ruptura en los años 1899 y 1900: es decir que contribuye a acercarnos a la reconstrucción genética de la historia del PS a través de sus conflictos. ${ }^{36}$ La recuperación de este debate muestra, primero, que la posición socialista de las "dos patas", la política y la sindical, tiene una historia que estuvo marcada por

36. POY, Lucas y ASQUINI, Sabrina, "La experiencia 'colectivista'. Orígenes, desarrollo y alcances de la primera ruptura obrera en el Partido Socialista argentino, 18961900", en PIMSA. Documentos y comunicaciones, Buenos Aires, 2015, pp. 53-89. 
tensiones donde los argumentos fueron forjándose al calor de la discusión. Segundo, que entre 1902 y 1904 el debate no era aun con los sindicalistas: de hecho algunos de sus futuros referentes, como Bartolomé Bosio, se contaban entre los principales defensores de la postura de la dirección del partido. En tercer lugar, que este debate quedó obturado en 1904, luego de la elección de Palacios, y se planteó luego en términos relativamente distintos, con otro armazón conceptual, el de los sindicalistas.

Pero creemos que el examen de esta discusión también plantea algunos elementos valiosos para la elaboración de hipótesis más amplias sobre este período de la historia del movimiento obrero local. Las reiteradas referencias, a lo largo del debate, al hecho de que desenvolver una agitación política en los gremios implicaba "ir contra la corriente" prueban un rasgo que consideramos fundamental para comprender la situación de la clase trabajadora de la época. De hecho, hay rastros de esta desconfianza y resquemor hacia la política desde las fechas más tempranas: por ejemplo, en el debate interno que tuvieron los socialistas a principios de la década de 1890, cuando el Verein Vorwärts y luego otros grupos plantearon que, debido al escaso desarrollo del capitalismo local, no estaban dadas las condiciones para formar una organización política, y había que limitarse a lo económico. También, y más abiertamente, en el planteo de los colectivistas de 1899, que daban a entender las dificultades que encontraban en la actividad cotidiana cuando tenían que plantear a los trabajadores la necesidad de naturalizarse y participar en la lucha política.

En cierta medida esta desconfianza y resquemor expresaba la tendencia de los trabajadores a lograr una unidad en la lucha, rechazando las divisiones políticas como algo ajeno y viéndolas como responsables de la desunión. Pero también entraban en juego otras cuestiones, como afinidades étnicas y nacionales, sentimientos religiosos $\mathrm{y}$ las características fraudulentas del régimen político. Fueran cuales fuesen sus causas $-y$ es una cuestión que requiere el más serio examen en lo sucesivo- es indudable que la existencia de esas presiones "antipolíticas" en las propias filas obreras operó como un factor clave para comprender las disputas políticas entre las diferentes corrientes, así como las tensiones en cada una de ellas.

En efecto, y tal como apuntaban muchos de los participantes en el debate, los militantes anarquistas sabían aprovecharse de esta resistencia a la prédica de los socialistas para hacer avanzar sus posiciones, con un discurso que no era menos político pero sí cuestionaba a los "políticos" en general. En la misma línea, ¿no puede pensarse que el sindicalismo revolucionario podría, apenas unos años más tarde, proporcionar un esqueleto teórico y conceptual capaz de canalizar buena parte de este rechazo a la política, al tiempo que se apoyaba en las tendencias a la unidad de los trabajadores?

Una lectura de este tipo nos permitiría poner la historia intelectual de las discusiones al interior de las izquierdas en relación directa con el propio desarrollo de la clase trabajadora en la cual ellas intervenían. Puesto el problema en esta perspectiva, por otra parte, vemos que en realidad no se trata de explicar qué ocurrió para que los socialistas perdieran una influencia en la clase obrera que se da por supuesta. En realidad, y tal como muestra la 
investigación histórica, los socialistas siempre tuvieron dificultades para desenvolver su propuesta "política" en el seno de la clase trabajadora y en particular en el seno de los trabajadores organizados. Es esa disputa por la identidad obrera entre diversas tendencias $\mathrm{y}$ orientaciones, en todo caso, lo que debe reconstruirse: aún queda mucho por hacer.

$\propto \ddot{\ell} \propto$

Recibido: 28 - 03 - 2016

Aceptado: 06 - 07 - 2016

Publicado: 30 - 12 - 2016 


\section{Bibliografía}

BELKIN, Alejandro, "El debate Patroni-Dickmann (1904). Partido y sindicatos en el socialismo argentino", ponencia presentada en las XI Jornadas Interescuelas de Historia, Tucumán, 2007

BELKIN, Alejandro, Sobre los orígenes del sindicalismo revolucionario en Argentina, Ediciones del Centro Cultural de la Cooperación, Buenos Aires, 2007.

CAMARERO, Hernán, "Socialismo y movimiento sindical: una articulación débil. La COA y sus relaciones con el PS durante la década de 1920”, en CAMARERO, Hernán y HERRERA, Carlos, El Partido Socialista en Argentina, Prometeo, Buenos Aires, 2005.

CAMARERO, Hernán y HERRERA, Carlos, El Partido Socialista en Argentina, Prometeo, Buenos Aires, 2005.

CAMARERO, Hernán y SCHNEIDER, Alejandro, La polémica Penelón-Marotta (marxismo y sindicalismo soreliano, 1912-1918), CEAL, Buenos Aires, 1991.

Congrès international socialiste des travailleurs et des chambres syndicales ouvrières, Londres 26 juillet-2 aout 1896 [Reprint], Minkoff, Ginebra, 1980.

MAROTTA, Sebastián, El movimiento sindical argentino, Lacio, Buenos Aires, 1960.

MARTÍNEZ MAZZOLA, Ricardo, "La neutralidad como problema y como solución. La política gremial del Partido Socialista después de la ruptura sindicalista”, Identidades, Comodoro Rivadavia, 2011, No 1, pp. 2-20.

MILNER, Susan, The dilemmas of internationalism: French syndicalism and the international labour movement, 1900-1914, Berg, Nueva York, 1990.

POY, Lucas, Los orígenes de la clase obrera argentina, Imago Mundi, Buenos Aires, 2014.

POY, Lucas, "E1 Partido Socialista y las huelgas: una relación incómoda”, Archivos de historia del movimiento obrero y la izquierda, Buenos Aires, 2015, No 6, pp. 31-51.

POY, Lucas y ASQUINI, Sabrina, "La experiencia 'colectivista'. Orígenes, desarrollo y alcances de la primera ruptura obrera en el Partido Socialista argentino, 1896-1900”, en PIMSA. Documentos y comunicaciones, Buenos Aires, 2015, pp. 53-89.

TORTTI, María Cristina, Estrategia del Partido Socialista: reformismo politico y reformismo sindical, CEAL, Buenos Aires, 1989. 